\title{
Construction of Landscape Fire Security Patterns for Minority Settlements: a case study of reconstruction plan of Xiaozhai village in Guangxi
}

\author{
Manni $\mathrm{Wu}^{1}$, Wenjun Zheng ${ }^{1, *}$, Zonglin Liu ${ }^{1}$ \\ ${ }^{1}$ College of Tourism \& Landscape Architecture, Guilin University of Technology, Guilin 541004, China
}

\begin{abstract}
Minority settlements have good local landscape features and rich cultural heritage. However, due to complex geographical conditions and lagging economic development, there are many potential security threats in their human settlements. Based on the landscape ecological security pattern theory, aiming at eliminating the practical dilemma of frequent fires and difficult rescue in mountainous settlements in southwestern China, this paper proposes a planning idea to improve the settlement environment's own disaster resilience and ecological endurance ability through the adjustment of landscape pattern. Taking the reconstruction planning and design of Xiaozhai Village in Longji of Guangxi province as an example, based on the geographical structure and resource characteristics of the village, a four-in-one landscape fire security pattern for mountain settlement is constructed, including building group, road evacuation system, natural fire protection network of water system and biological fire protection forest belt. The study provides a reference for the protection, renewal and re-planning of minority settlement.
\end{abstract}

\section{Introduction}

The ecological environment and cultural forms of ethnic minority areas are complex, which has precious vernacular landscape resources and is called cultural heritage protection areas. Because the residential areas are mostly mountains, plateaus, and deserts far from the city, the spatial patterns of settlements often conform to the mountainous terrain, agricultural production, and religious activities ${ }^{[1]}$. With special geographical conditions and without unified planning, the layout of traditional settlements have distinct ethnic and regional marks. At the same time, problems such as low living quality and backward social and economic development also exist ${ }^{[2]}$. Under the impact of modern civilization, the contradiction between the relatively fragile living environment and the increasing demand for human settlements has become increasingly prominent. In recent years, with the renewal of life style and the continuous increase of daily energy types and consumption, fire has become the most frequent disaster of ethnic minority settlements in southwest mountain areas of China. Moreover, due to severe terrain conditions and traffic restrictions, modern fire equipment and technical means are difficult to be applied in these areas.

How to eliminate the hidden dangers of traditional settlement survival from the root cause is an important issue that needs to be considered urgently in the science of human settlements. From the perspective of landscape ecology, the landscape pattern has a decisive role in the distribution and combination of regional resources and physical environment, and has a profound impact on the ability of anti-interference and recovery. Through the planning and management of the spatial pattern, we can control and improve all kinds of ecological environment problems of the area ${ }^{[3]}$. Based on the theory of landscape ecological security pattern, taking the post-fire reconstruction planning and design of Xiaozhai Village, Longji Town, Longsheng Autonomous County, Guangxi as an example, the fire security pattern of mountain settlement landscape is constructed, which will provide reference and inspiration for landscape protection, renewal and re-planning of ethnic minority settlements.

\section{Fire troubles in Minority settlements}

Hunan, Guangxi and Guizhou, which is located in the southwest of China, is an important area where ethnic minorities live. After the 1990s, ethnic villages in this area were deeply plagued by fires, resulting in a great loss of resources.

According to statistics, from 2004 to 2006, there were more than 20 serious fires in ethnic minority villages in Northwest Guangxi, with 1672 households affected; from 2014 to 2019, there were 120 fires in ethnic villages in the whole autonomous region, resulting in 37 deaths and direct economic and property losses of more than 11 million yuan. From 1991 to 2008, 1,701 rural fires occurred in Miao and Dong Autonomous Prefecture in Southeast Guizhou, resulting in 294 deaths and 189 injuries, including 115 major fires and 70

\footnotetext{
* Corresponding author: 149480860@qq.com
} 
Catastrophic fires. From 2010 to 2014, four major fires broke out in Huaihua and Xiangxi, Hunan province, destroying more than 150 buildings ${ }^{[4]}$.

The lag of traditional life experience under the change of civilization and the incompatibility of new technologies with the rural environment is the essential reason for the fire dilemma of the ethnic minority settlements in Xiang, Gui and Qian area. In the early stages of social development, villages of various nationalities have formed a relatively stable and balanced civil fire protection system by virtue of their local wisdom. For example, locating villages near water sources, drawing water into villages, digging ponds, and building barns on paddy fields; using religious taboos, and customary laws to control fire using, and formulating punitive measures. However, as the population grows and the scale of the village has expanded, some ponds and fields have been filled to build houses; coupled with the popularity of electricity, the water source has dried up, and the effectiveness of traditional folk fire protection facilities has gradually weakened. As early as 1984, the Ministry of Culture and the Ministry of Public Security issued the "fire management rules for ancient buildings", which put forward the general requirements for fire safety of ancient buildings from two aspects of fire source control and application of fire fighting facilities. Subsequently, local governments at all levels have successively issued various fire prevention regulations, fire management regulations, and fire protection construction plans. The theoretical level has formed a relatively complete system, and a large amount of capital has been invested in the construction of pilot projects. These efforts have achieved some results, but in recent years, fire statistics have shown that the introduction of modern fire protection systems has shown more limitations in the practical application of ethnic areas, and the overall frequency of fires and heavy fires have not been significantly curbed ${ }^{[5]}$.

\section{Analysis of the human settlements and Fire Risk of Xiaozhai Village}

\subsection{Human settlements of Xiaozhai Village}

Xiaozhai Village is located in Longji Terraced Scenic Area, Longsheng Autonomous County, Guangxi Zhuang Autonomous Region, $110^{\circ} 09^{\prime}$ east longitude and $25^{\circ} 49^{\prime}$ north latitude. The village is located in the midsubtropical monsoon climate zone. The annual average temperature is $17.1^{\circ} \mathrm{C}$, the average temperature in July is $25.4^{\circ} \mathrm{C}$, the annual average sunshine hours are 1223.3 hours, the annual rainfall is $156.7 \mathrm{~mm}$, and the frost-free period is 314 days. The village covers an area of about 27.9 hectares, with an altitude of $795-1008 \mathrm{~m}$ and a vertical height difference of $213 \mathrm{~m}$. The slopes are mainly $5-15^{\circ}$ slope and $15-35^{\circ}$ steep slope, and the slope aspect is mainly in the West and South (Fig. 1). The village is surrounded by mountains in the east, west and north, with valleys in the south. There are terraced fields, dwellings built on mountains, and three streams pass through the village. The village is rich in vegetation resources and belongs to the mid-subtropical evergreen vegetation area. Arbor mainly contains Magnoliaceae, Theaceae and Lauraceae. Shrub mainly contains Litsea pungens, Camellia chekiangoleosa and Lespedeza bicolor. Miscanthus floridulus, Blechnum orientale and Arundinella anomala are the main herbs. The village was built at the end of the Ming Dynasty and has a population of about 1300. It is the settlement of Pan's Red Yao nationality. The Red Yao culture in the village is distinct and well protected. It was selected into the fourth batch of Chinese traditional villages in 2017.

\subsection{Fire risk analysis of Xiaozhai Village}

On September 30, 2018, a fire broke out in Xiaozhai village. The first fire point was in the middle of the village. Then, the fire spread rapidly around, burning 29 residential buildings. In order to prevent the fire from spreading, 19 houses were demolished and the core area of the village was seriously damaged (Fig. 2). Through the comprehensive analysis of the site environment, it is found that in addition to human factors, the settlement space also has the following objective hidden danger of fire.

First of all, the building has a low fire rating and insufficient spacing. The original residential houses of Xiaozhai Village were all wooden structures with poor fire resistance. The buildings in the villages were dense, and once ignition, they quickly formed a spreading trend; lacking emergency refuge space, it is easy to cause residents to be trapped and endanger their lives.

Secondly, there is insufficient water for fire fighting. Although three small creeks pass through the village, the runoff is relatively small, and the width of the stream is about $1.5 \mathrm{~m}$. The natural water system is not up to the standard for fire protection, and the village lacks emergency water.

On the other hand, due to terrain constraints, the settlement structure of Xiaozhai Village is relatively closed, and the overall traffic conditions are poor. There is only one sightseeing route outside the village. The roads in the village are not open to traffic. Fire trucks cannot reach the village when the fire breaks out. It takes a certain amount of time for firefighters to walk into the village on foot, and there are not enough fire evacuation channels, which greatly affects the rescue efficiency.

Moreover, the scattered vegetation in the village has poor fire resistance and fails to play a protective and isolation role.

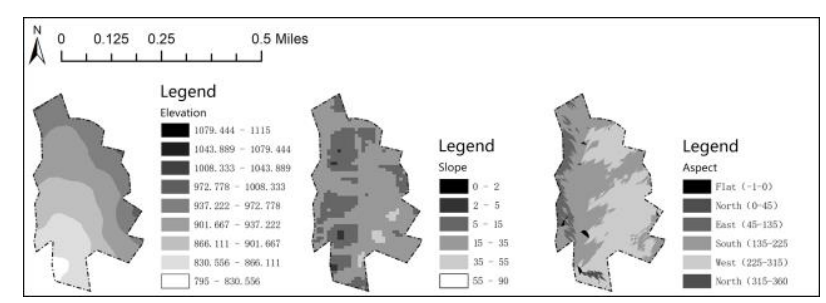

Fig. 1. Topographic analysis of Xiaozhai Village 


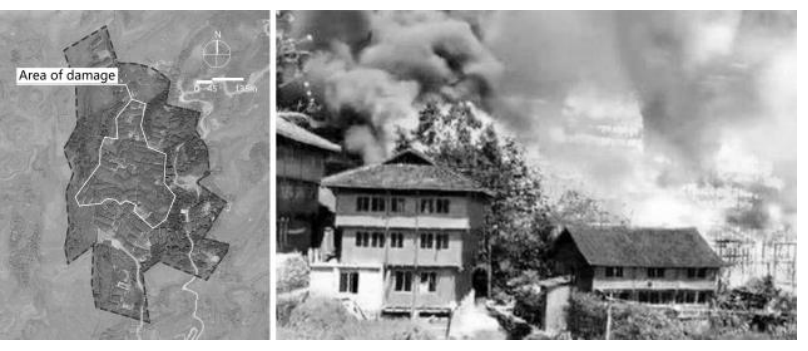

Fig. 2. Fire damage area and scene photos of Xiaozhai Village

\section{Construction of landscape fire security pattern in Xiaozhai Village}

There is a potential spatial pattern composed of some key parts, points, and positional relationships in the landscape, which plays a key role in maintaining and controlling a certain ecological process, and is called a security pattern ${ }^{[6]}$. The traditional settlements of ethnic minorities formed spontaneously in conformity with the terrain and the spatial layout was relatively flexible, but there were often many potential safety hazards, which made the villages threatened by various natural or manmade disasters. The post-disaster reconstruction planning and design of Xiaozhai involves the reconstruction of damaged houses, green space system planning, protection, repair and utilization of landscape resources, and the establishment of basic services related to the safe refuge site system. Taking this opportunity to identify, adjust and optimize the key nodes that can form a fire self-rescue function in the settlement environment is an effective way to strengthen the village's ability to resist disasters from the roots.

The analysis of the causes of fire in Xiaozhai Village shows that over-dense buildings, flammable building materials, inadequate water reserves, inconvenient road traffic, and the inability to use high-standard fire-fighting equipment as basic material guarantees are the key factors leading to the spread of fire. This study through the redistribution of building groups, the improvement of road systems, the planning of water network, and the layout of biological fire belts to improve the fire resistance of each local space, and then superimpose the various levels and enhance the landscape to form a fourin-one landscape fire prevention security pattern (Fig. 3, Fig. 4).
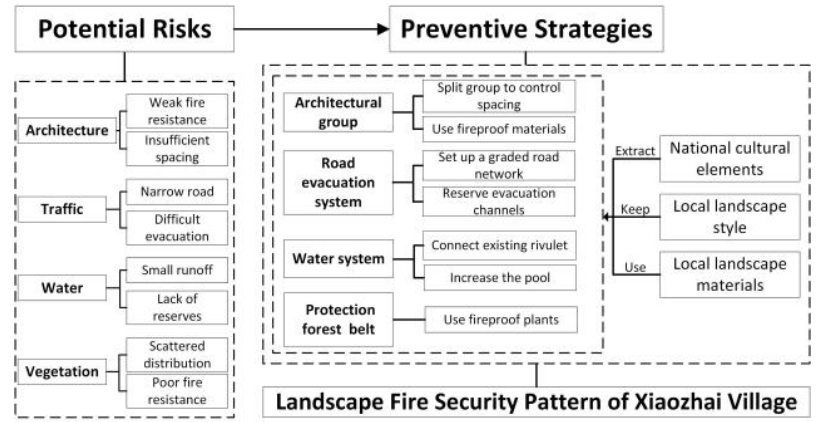

Fig. 3. Construction strategy of landscape fire safety pattern in Xiaozhai Village

\subsection{Fire protection system construction}

\subsubsection{Architectural group planning}

Longji Xiaozhai Village's architectural form is dominated by dry hurdles, which are usually arranged freely along with the terrain, and the overall distribution is relatively concentrated. The area damaged by this fire is mainly the core building area of Xiaozhai Village, with a total of 48 damaged buildings. In order to restore the life needs of Xiaozhai Village, and at the same time integrate the village layout and maintain the ethnic style, it is planned to re-divide the buildings in the village into 5 groups, and the area of a single group shall not exceed $15000 \mathrm{~m}^{2}$. According to the terrain of the site, the newlybuilt groups will be arranged with a slope of $0 \%-30 \%$ and $90^{\circ}-270^{\circ}$ (southwest, south, southeast) orientation. The building groups are distributed on both sides of the main road, the distance between the groups is more than 15 meters, the building density is controlled within $28 \%$, and each group has $800 \mathrm{~m}^{2}$ of land for disaster prevention and danger avoidance. The distance between the buildings in the group is no less than $4 \mathrm{~m}$ to block the fire. Newly built and repaired buildings were changed from wooden structures to brick-wood structures, and fireproof coatings were used on the surface of the houses to enhance the building's own fireproof performance while retaining the characteristics of dry-style residential buildings.

\subsubsection{Road evacuation system planning}

The re-planned Xiaozhai Village road system is divided into three levels. The first-grade road is 4 meters wide and surrounds the entire village. It runs from north to south and is the main traffic route and fire lane. The secondary roads are 2.5 to 3 meters wide and are connected to the main road in the east-west direction. They are used to divide and connect building groups and prevent the spread of fire. The third-level road is a sidewalk between buildings and various landscape nodes, planks, etc., about 1.5 to 2 meters wide. The transportation system composed of three-tier road network can not only meet the traffic demand, but also play the role of flame retardant, control the distance between houses, and evacuate people quickly in the event of fire, so as to ensure that the villagers can quickly go to the planned disaster prevention space.

\subsubsection{Natural fire prevention network planning of water system}

Since ancient times, water has been the main tool to control fire. Chinese have already known how to control water, improve the natural water environment to build water conservancy and garden landscaping. There are three natural streams from north to south in Xiaozhai Village, but the locations are relatively scattered and isolated from each other, so they cannot be used efficiently. Many buildings in the village are difficult to get timely rescue because they are far away from the 
water source. The newly planned water system network is based on the three original streams on the site, and the water channels surrounding most of the buildings are constructed according to the terrain, so that each family lives near the water. In order to prevent the stream from running dry during the dry season and cause the water network to dry up, pools were planned as backup water sources in each building group centre. The combination of streams and artificial canals and reservoirs can form a network of water throughout the village, and strive to meet the needs of fire water sources while also bringing good landscape effects and adding vitality to the settlement.

\subsection{4 biological fire protection forest belt planning}

The original forest land in Xiaozhai Village is mostly distributed outside the village, with sparse vegetation and low canopy density, which fails to produce protective effect. It is planned to set up a biological fire prevention forest belt with a width of $12 \mathrm{~m}$ on the periphery of each building group to connect the original evergreen vegetation community of the site and cooperate with the road to prevent the spread and expansion of fire. The biological fire belt is a kind of ecological fire protection project that uses the fire protection function of plants to achieve flame retardance. Compared with other measures, the construction period is longer, but it can produce a stable and lasting effect. In this plan, Schima superba is selected as the main tree species of fire prevention forest belt. Schima superba is a kind of tree species with strong fire resistance, luxuriant branches and leaves, large canopy density and high moisture content of litter. Moreover, the tree species is suitable for planting in southern mountainous areas ${ }^{[7]}$, and has high ecological benefits and ornamental value.

\subsection{Fire protection system construction}

The formation and evolution of the landscape of ethnic minority settlements blends into the mountains and waters, adapts to nature, and its regional landscape culture has unique vitality and high protection value. In the secondary planning, it is necessary to comprehensively consider the protection, restoration and utilization of local landscape resources. This study is committed to solve the problem of village fire, at the same time, to integrate local cultural elements and use local materials to optimize the landscape of Xiaozhai village. In this plan, a total of 13 landscape nodes were designed (Fig. 5), some of which rely on the construction of a fire protection network to achieve a combination of function and form.

For example, Panwangyan Square, located in the centre of the reconstruction, is the largest intersection point of the largest public space in the whole site and the water system network in the village. Use its relatively flat topography to create a space for residents' living and disaster prevention and avoidance, while enhancing fire safety functions and providing an event venue for villagers to hold festivals and build the core of the village landscape. The whole square is supported by a wooden structure as a plane, and the surrounding buildings extract the elements of the Red Yao ethnic Dry column architecture and deform it. The wind and rain bridge built along the water in the northeast side and the buildings of bole fences in the south side form a circular enclosed space. The curved pool under the wind and rain bridge provides water for firefighting while creating a water feature (Fig. 6).

The slopes in the east and west of the village have large areas of terraced fields or woodlands, which provide rich space for evacuating people and appreciating scenery. The plan is to build the Yanxiawu Terrace Boardwalk based on the mountain on the west side, and build Hear the Wind Sing Boardwalk in the woodland on the east side. The walkway, with a width of 3 meters, will be used as an important sightseeing route and fire safety passage connecting the landscape inside and outside the village. An observation deck is set at an appropriate distance to overlook the terrace landscape and overlook the whole village (Fig. 7).

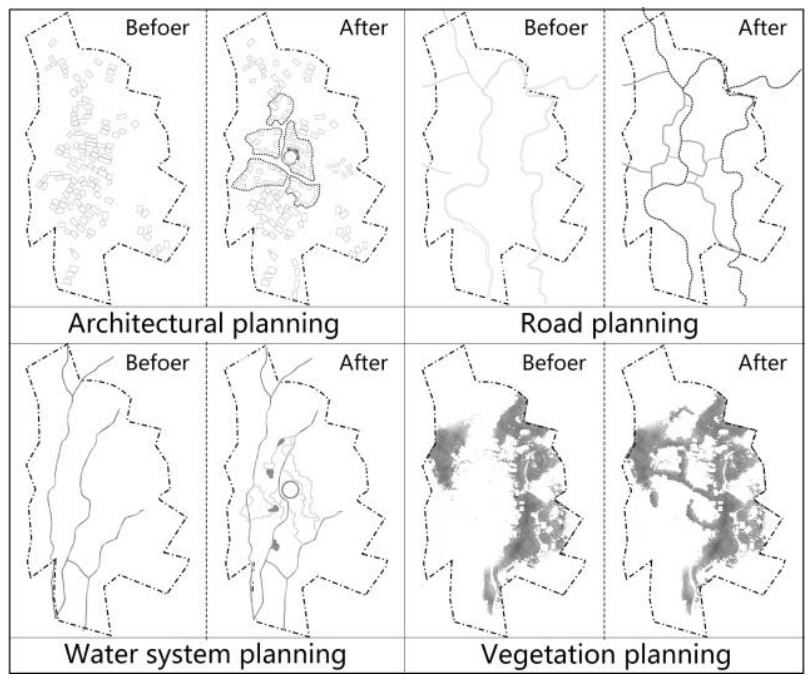

Fig. 4. Xiaozhai Village fire system planning before and after comparison

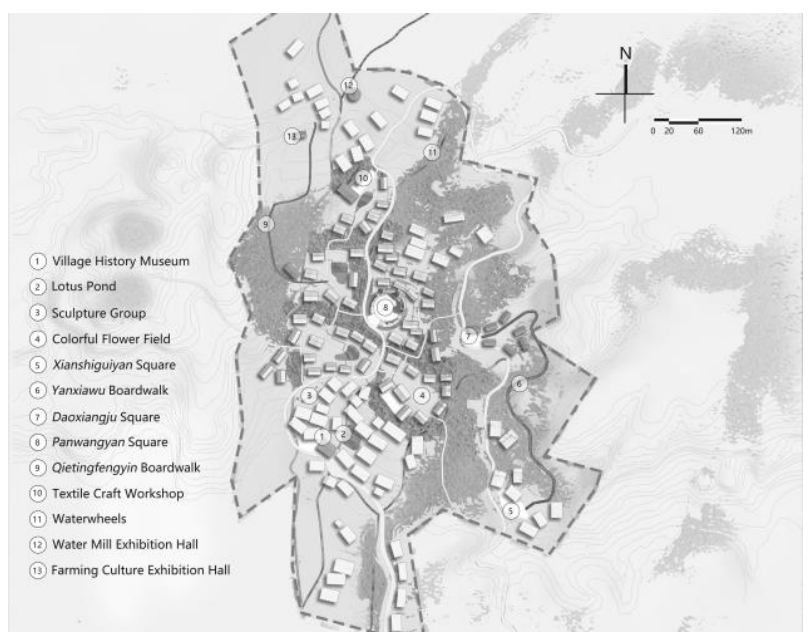

Fig. 5. The overall plan of xiaozhai Village post-disaster reconstruction planning and design 

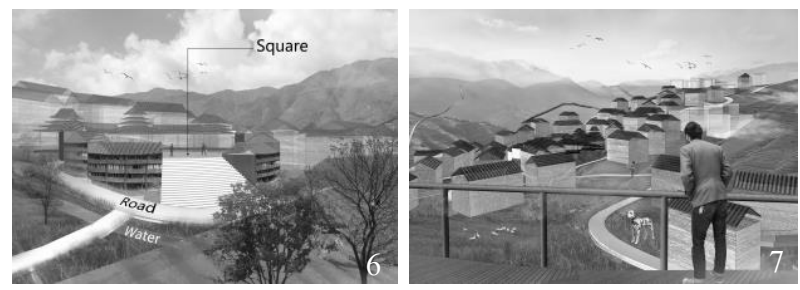

Fig. 6. Renderings of Panwang Square

Fig. 7. Renderings of Boardwalk

\section{Conclusion}

Habitat security is the primary problem of environmental protection and development of minority settlements. Due to the particularity of the geographical environment, culture, and economic environment, the construction of disaster prevention systems and infrastructure for minority settlements cannot be a simple copy of the urban method. For remote mountainous settlements that are prone to fire and difficult to rescue, a comprehensive disaster reduction method combining engineering measures and non-engineering measures should be taken. It should make full use of its own geographical structure and resource characteristics, reasonably plan residential partitions and firefighting passages, transform natural water systems, use fireproof building materials and refractory plants, and build a fire safety pattern for settlement landscapes. Eventually, it will improve its anti-risk ability and ecological endurance ability to deal with sudden catastrophes from the root causes, and shift the passive adaptation of Human-Environment to active regulation and scientific management, so as to create a safe and liveable beautiful rural environment.

\section{Acknowledgements}

Supported by:

Humanities and Social Science Project of Ministry of Education of China (19YJC850027);

Guangxi Natural Science Foundation Project

(No.2018GXNSFAA050068);

Guilin Science and Technology Major Project

(20180102-2)

\section{References}

1. L.J. Wan, X. Li, The Vernacular Landscape Renewal of Minority Settlement Space [J]. Chinese Landscape Architecture, 27, 91-93(2011)

2. P.L. Liu, C.L. Liu, B.H. Li, Y.Y. Deng, X.Y. Sheng, $\mathrm{Z}$. $\mathrm{Hu}$, Characteristic and Genes - Analysis of Traditional Settlements' Landscapes in Chinese Minority Areas [J]. Scientia Geographica Sinica, 30,810-817(2010)

3. K.P. Ma, B.J. Fu, X.Y. Li, W.B. Guan, The regional pattern for ecological security (RPES) : the concept and theoretical basis [J]. Acta Ecologica Sinica,761768(2004)
4. W.X. Pan, On the lag of Cultural adaptation in the process of National Development-- taking the Fire of ethnic Minority villages in Hunan, Guangxi and Guizhou as an example [J]. Academic Forum, 37,145-149(2014)

5. D.H. Wu, J. Guo, "Failure"of Formal System under Conflagration—Case Study of Ethnic Villages in Southeast Guizhou [J]. Journal of Northwest University for Nationalities(Philosophy and Social Science), 93-98(2013)

6. K.J. Yu, Landscape Ecological Security Patterns in Biological Conservation [J]. Acta Ecologica Sinica ,10-17(1999)

7. Y.F. Zhou,Study on Mechanism of Fire-preventing Forest Belts of Schima superba [D]. (Zhejiang A\&F University, 2007) 